\title{
COMMENT
}

POLICING Ensure crime-

prediction algorithms are fair and safe $\mathbf{p . 4 5 8}$
HISTORY How Europe shaped US research universities over 150 years $\mathbf{p . 4 6 1}$
BIOETHICS The role of

democracy in humanembryo research $\mathbf{p . 4 6 2}$
SUSTAINABILITY Tax

goods that harm the environment p.464

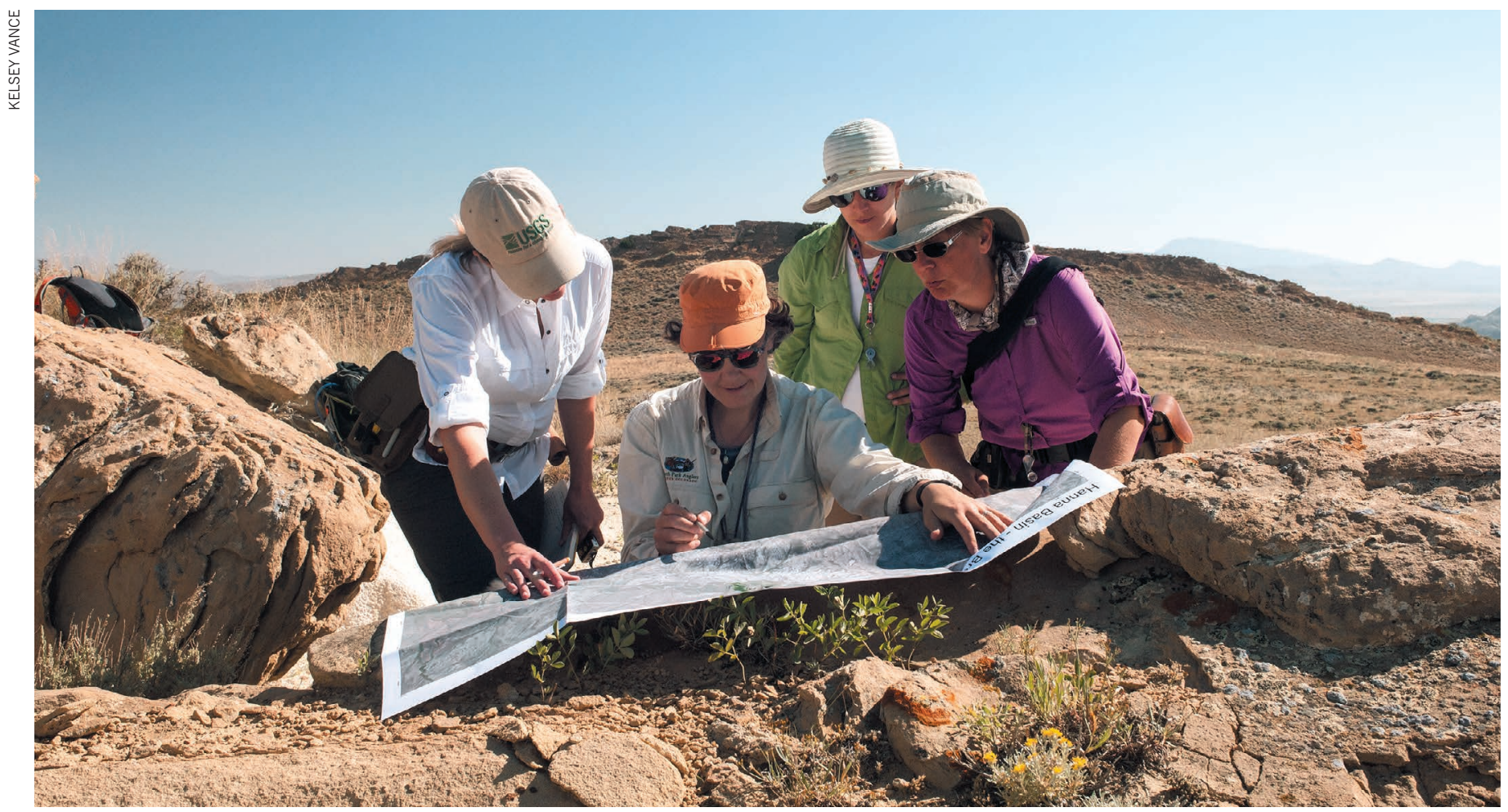

US geoscientists on an expedition in Wyoming as part of the Bearded Lady Project, which raises awareness about inequality in science.

\section{Journals invite too few women to referee}

\section{Jory Lerback and Brooks Hanson present an analysis that reveals evidence of gender bias in peer review for scholarly publications.}

$\mathrm{B}$ ias - explicit and implicit - is an important cause of the underrepresentation of women and minorities in science, technology, engineering and mathematics (STEM) $)^{1}$. Women and minorities are disadvantaged in hiring or promotion decisions, awarding of grants, invitations to conferences, nominations for awards, and forming professional collaborations ${ }^{2}$. These scholarly activities are crucial for career advancement and job retention.

Another career-building activity is serving as a peer reviewer for publications.
This develops writing skills and expertise through exposure to other manuscripts, and fosters relationships with fellow scholars and scientific leaders. Such activities are especially important for young scientists.

But most publishers do not collect gender, age or any other relevant demographic information from authors or reviewers. So biases here have been harder to pin down. Most studies of gender inequality in publishing have assigned gender to authors ${ }^{3,4}$ but have lacked information on age. This is important because many fields have only recently seen increases in participation of women

Here we present evidence that women of all ages have fewer opportunities to take part in peer review. Using a large data set that includes the genders and ages of authors and reviewers from 2012 to 2015 for the journals of the American Geophysical Union (AGU), we show that women were used less as reviewers than expected (on the basis of their proportion of membership of the society and as published authors in AGU journals). The bias is a result of authors and editors, especially male ones, suggesting 
women as reviewers less often, and a slightly higher decline rate among women in each age group when asked.

These findings underline the need for efforts to increase female scientists' engagement in manuscript reviewing to help in the advancement and retention of women in science.

\section{THE DATA SET}

With 20 journals and nearly 6,000 papers published per year, the AGU is the largest society publisher of Earth and space science. Like many other publishers, it does not ask authors and reviewers to report their age or gender. But the AGU is the largest Earth and space society in the world and it has asked its members to self-report this information since 2013. Overall, $79 \%$ of members from 2013 to 2015 (59,316 people) reported both. We call this the AGU membership data set.

We have gender and age data on a further 38,115 individuals who have AGU accounts and who engaged in AGU activities after 2011 (see Supplementary Information; go.nature.com/2ifshqs). We refer to this group combined with the membership data set as the AGU 'all accounts' data set. Checks on random samples indicate that the gender distribution of members choosing not to disclose this information is similar to that of members who did, and that the gender and age information were reported accurately.

To reveal gender and age data on authors and reviewers between 2012 and 2015, we merged data on their activities (the 'editorial' data set) with the all-accounts data set using unique e-mail information. This merged data set represents the ages (at time of activity) and genders of 106,305 authors across all submitted manuscripts, 24,368 distinct authors, 62,552 reviews and 14,919 distinct reviewers, as well as 97,083 reviewer suggestions by authors and 118,873 reviewer requests by editors. The data set represents $35 \%$ of all distinct authors, $57 \%$ of distinct reviewers, $50 \%$ of all authors and $69 \%$ of all reviews completed.

These data represent a significant reference sample of engaged, practising and aspiring Earth and space scientists, even though they do not capture all author and reviewer interactions. Membership of the AGU or an affiliated society is required to submit an abstract to the annual meeting, one of the largest scientific conferences worldwide (22,000 presentations and 25,000 attendees in 2015), and all attendees must create an AGU account. AGU membership is dominated by academic and government scientists ( $77 \%$, with just $5 \%$ in industry) and by scientists in the United States (59\%), Japan (5\%), the United Kingdom (4\%) and the rest of Europe (15\%). Proportions are similar for the all-accounts data set.

In short, the AGU makes a good proxy for STEM demographics in the United States.

\section{UNEQUAL OPPORTUNITIES}

Despite journals of the American Geophysical Union (AGU) accepting women's papers at a higher rate than they do men's across all age groups (A), both female and male authors (B) and editors (C) suggest and invite fewer women - of every age — to referee than are available (D). Women also say 'no' more frequently than men in the same age group when asked by the AGU to do peer review (E).

A First-author acceptance rate by gender and age

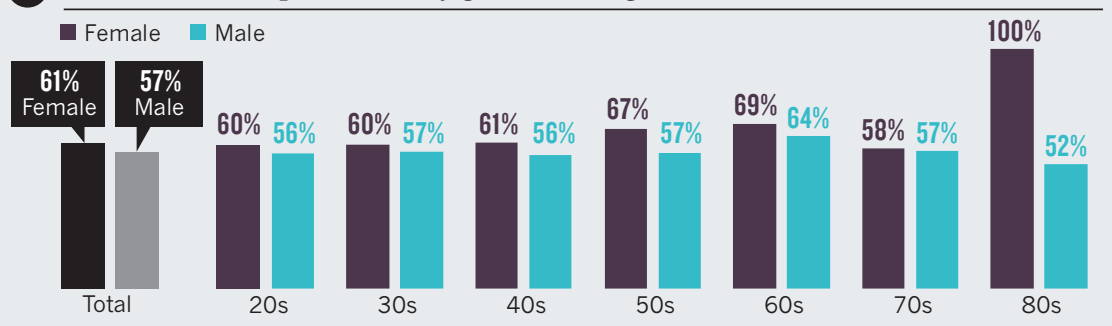

B Female reviewers suggested by authors

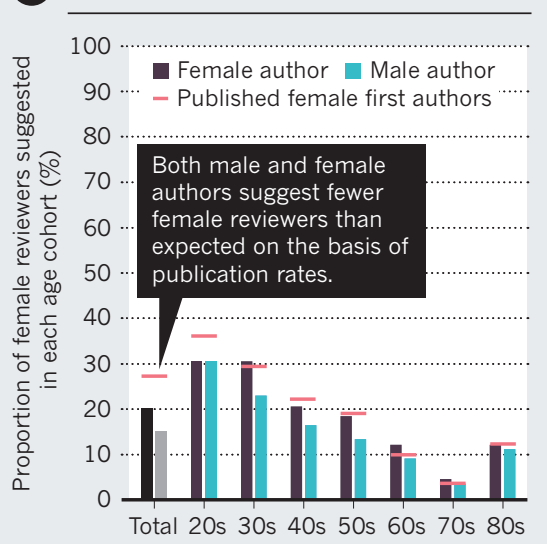

C Female reviewers invited by editors
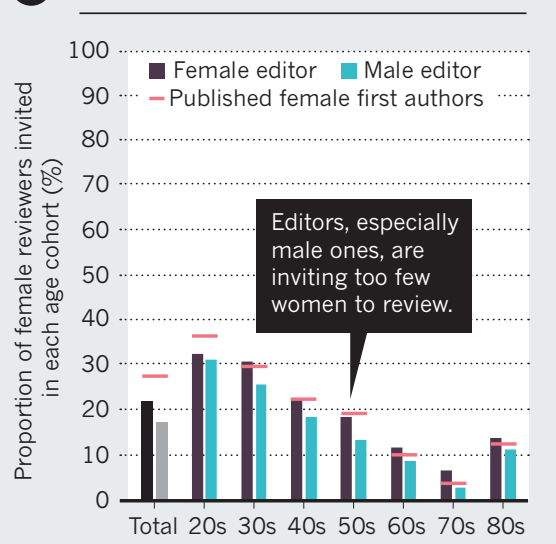

(D) Too few women are doing peer review

$\begin{array}{ll}\text { FEMALE } & \text { MALE } \\ \text { Reviewers } & \text { Reviewers } \\ \text { Published first authors } & \text { Published first authors }\end{array}$

(E) Decline rate of invited reviewers

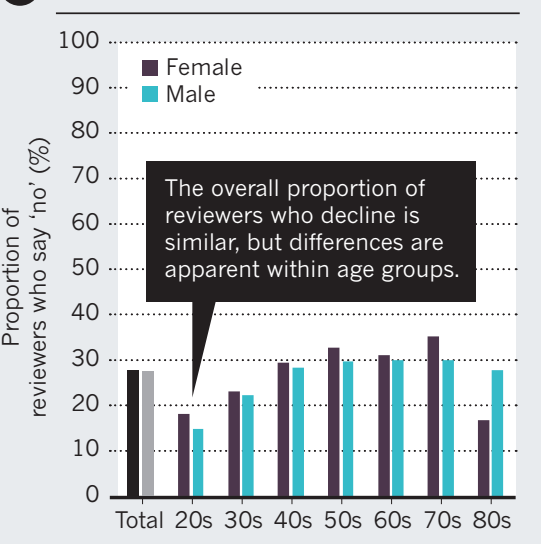

From 2013 to $2015,28 \%$ of members, on average, were women. This is close to the ratio of scientists and engineers employed in the United States (29\% in 2013) $)^{5}$ and USemployed Earth and space scientists (25\% in $2014)^{6}$. The gender ratio of AGU membership decreases with age. The older cohorts have fewer women, reflecting historically higher barriers to inclusion of women and the greater rate of attrition of women from Earth and space science careers (known as the leaky pipeline $)^{2}$. The youngest age group in 2015 (20s), by contrast, is $45 \%$ female. We have not extrapolated our analysis to the complete editorial data set because we have no age data for these additional participants (even if we could assign gender).

\section{SUBMISSIONS AND PUBLICATIONS}

We matched the gender and age of 7,196 distinct first authors who submitted 22,067 manuscripts in 2012-15. In the geosciences, first-authored papers are particularly important to career development, hiring and promotion decisions. In most cases, the first author is also the corresponding author ( $89 \%$ in our data set). Women made up $26 \%$ of submitting first authors (they accounted 
for $23 \%$ of all submitting authors). Overall, women participated less as authors relative to the make-up of the membership and allaccounts data sets in aggregate and across all age cohorts. Female first authors $(n=2,859)$ on average also submitted 0.79 fewer papers per person in the four-year period than male first authors $(n=8,098)$.

The acceptance rate for female firstauthored papers was higher than for male ones (61\% compared with 57\%). Negligible differences have been found by other studies in biology and medicine $e^{7}$. In our data, female first authors had higher acceptance rates across all age groups, and the differences were significant at $P<0.05$ for all age cohorts under 60 . This difference in acceptance rates pertained (although not always with significance) across papers with any size of author group, including single-author papers. Acceptance rates were similar regardless of the gender of the editor or reviewers.

One might interpret the difference in acceptance rates in two ways. It could imply that female AGU authors are enjoying 'reverse sex discrimination', as suggested by recent studies (see, for example, ref. 8). Or - and this is the possibility we favour - the higher acceptance rates reflect the authors' more considered approach when submitting manuscripts, including better targeting of papers to a journal. Several studies have shown that groups who are expecting obstacles put greater effort into preparation or take fewer risks ${ }^{9}$. And our data show that women submitted fewer papers than men. A doubleblinded reviewing process could shed more light on these factors.

\section{PEER REVIEW}

The gender ratio of reviewers should be similar to that of published authors of similar age and to the AGU membership. But women constituted $20 \%$ of all of the individual reviewers in 2012-15, substantially less than the proportion of distinct published female first authors (27\%), published authors (23\%) and AGU members (28\%) or all-accounts holders (29\%; see 'Unequal opportunities'). These lower proportions of female reviewers were evident across most ages and were statistically significant in the 50 s cohort. Thus, the lower participation by women as reviewers is not just because editors were seeking more-senior reviewers, who are predominantly male. Furthermore, men $(n=11,876)$ did more reviews per person (2.1 reviews) than did women ( $n=3,043 ; 1.8$ reviews).

There are two possible reasons for women's lower participation rates. First, authors and editors (or both) might have nominated fewer women in each age group to review (at the AGU, authors suggest reviewers at submission, and editors prepare a final list). Second, women might have declined invitations more often than men.
We found that the first reason contributed more to the discrepancy. Female first authors suggested female reviewers $21 \%$ of the time $(n=13,279)$; men suggested women just $15 \%$ of the time $(n=47,236)$. Unsurprisingly, whatever their gender, authors suggested reviewers in their 20 s only $1 \%$ of the time.

AGU editors invited just under one-third (29\%) of the author-recommended reviewers. Female editors recommended female reviewers $22 \%$ of the time versus $17 \%$ for male editors. Editors of both sexes were slightly more likely to invite the youngest reviewers (3\% of all recommendations). Of these young invitees, only $32 \%$ asked by female editors and $31 \%$ asked by male editors were women. This is lower than for the AGU membership or distinct published first authors. Recall: these differences did not translate into any sig-

nificant differences in "Reviewing the decisions on man- history is uscripts. Why authors important in and editors, especially recognition men, don't suggest insocieties or women to review may appointments reflect a number of as editors." factors, but it is often attributed at least in part to implicit bias ${ }^{1,10}$.

Women of almost every age declined their (fewer) invitations at a slightly higher rate than men in the same age group (except those over the age of 80). The differences were statistically significant for all ages except the $60 \mathrm{~s}$ and 80 s cohorts. For example, the decline rate for women was $22 \%$, versus $17 \%$ for men aged 20-30. Decline rates for both genders increased with age, although older cohorts included fewer women and proportionally more older men were asked to review. Therefore, the overall decline rate did not differ significantly. Thus, we do not believe that this results in a negative feedback loop, in which editors don't invite female reviewers because of they expect them to say 'no'.

The main reason scientists gave for refusing was their workload. The differences apparent in certain age groups could arise from the fact that women are more likely to be involved in other service activities at their institutions and to shoulder a greater burden of family and other social duties. The differences may also reflect varying approaches to risk or confidence ${ }^{2}$.

\section{WHAT NEXT}

The AGU is similar to many other large scientific societies. Thus we suggest that these results are broadly representative of gender and age differences across scholarly publishing, as well as grant evaluation. Other societies, funders and publishers should perform similar audits.

Participation as a reviewer for papers and grants has many benefits, particularly for early-career scientists. It is a chance to develop a relationship and make a positive impression with an editor, review-panel member or programme manager, who are typically senior scientists and are in turn likely to be involved in evaluating the reviewer's future papers and grants. The same relationships can be built with authors if the review is not anonymous (many at AGU are not) or the reviewer identifies themselves later to the authors. Reviews can also foster later collaborations (something not possible with double-blind reviews).

Reviewing also offers an important learning experience and a view of unpublished science, and helps improve communication and thinking. It provides positive feedback that a scholar is respected and participating in their field and fosters self-confidence, all of which lead to increased retention of women in geoscience ${ }^{2}$. Increasingly, there is a call to appreciate the time and effort that goes into reviewing. Hence reviewing history is important in recognition in societies or appointments as editors.

Hiring more female editors has helped the AGU to mitigate the disparity in recommendations. Publishers should consider further ways to train and educate their staff in combating bias. Encouraging authors and editors to invite more women to review, especially younger women, would be a start ${ }^{11}$. Funding agencies should similarly examine their practices. We encourage organizations and individuals to consider how the structures that propagate gender bias might affect other under-represented groups.

Jory Lerback is a graduate student at the University of Utah, Salt Lake City, Utah, USA, and was previously a data analyst at the American Geophysical Union. Brooks Hanson is director of publications at the American Geophysical Union, Washington $D C, U S A$.

1. Kaatz, A., Gutierrez, B. \& Carnes, M. Trends Pharmacol. Sci. 35, 371-373 (2014)

2. Holmes, M. A. O'Connell, S. \& Dutt, K. Women in the Geosciences: Practical, Positive Practices toward Parity (Wiley, 2015).

3. Filardo, G. et al. Br. Med. J. 352, i847 (2016).

4. Buckley, H. L., Sciligo, A. R., Adair, K. L., Case, B. S. \& Monks, J. M. NZ J. Ecol. 38, 335-339 (2014).

5. US National Science Foundation. Women, Minorities, and Persons with Disabilities in Science and Engineering (NCSES Scientists and Engineers Statistical Data System Publication, 2015); available at http://go.nature.com/2ie6agn

6. US Bureau of Labor Statistics. Women in the Laborforce: A Databook Report 1059 (2015).

7. Primack, R. B., Ellwood, E., Miller-Rushing, A. J., Marrs, R. \& Mulligan, A. Biol. Conserv. 142, 2415-2418 (2009).

8. Williams, W. M. \& Ceci. S. J. Proc. Natl Acad. Sci. USA 112, 5360-5365 (2015).

9. Freeman, R. B. \& Huang, W. J. Labor Econ. 33, S289-S318 (2015).

10.Dutt, K., Pfaff, D. L., Bernstein, A. F., Dillard, J. F. \& Block, C. J. Nature Geosci. 9, 805-808 (2016).

11.Fox, C. W., Burns, C. S. \& Meyer, J. A. Funct. Ecol. 30, 140-153 (2016).

Supplementary information accompanies this article online: see go.nature.com/2ifshqs. 


\section{COMMENT}

\section{CORRECTION}

In the graphic in the Comment 'Journals invite too few women to referee' (J. Lerback \& B. Hanson Nature 541, 455-457; 2017), the bar representing the acceptance rate for male first authors in their 70s was mislabelled. It should have read $57 \%$, not $67 \%$. 